\title{
iIR 84-2897
}

Al1106 048349

\section{Jefferson National Memorial Historical Site Analysis of Impact of Fire Safety Features}

Harold E. Nelson

U.S. DEPARTMENT OF COMMERCE

National Bureau of Standards

National Engineering Laboratory

Center for Fire Research

Gaithersburg, MD 20899

March 1985

Sponsored by:

National Park Service

Department of Interior

100

Washington, DC 20240

.456

$84-2897$

1985 



\section{JEFFERSON NATIONAL MEMORIAL HISTORIAL SITE ANALYSIS OF IMPACT OF FIRE SAFETY FEATURES}

Harold E. Nelson

U.S. DEPARTMENT OF COMMERCE

National Bureau of Standards

National Engineering Laboratory

Center for Fire Research

Gaithersburg, MD 20899

March 1985

Sponsored by:

National Park Service

Department of Interior

Washington, DC 20240

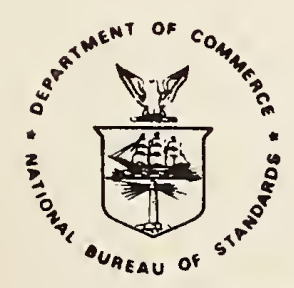

U.S. DEPARTMENT OF COMMERCE, Malcolm Baldrige, Secretary 

TABLE OF CONTENTS

$\underline{\text { Page }}$

List of Figures . . . . . . . . . . . . . . . . . . . . . . iv

List of Tables . . . . . . . . . . . . . . . . . . . . . v v

Foreward . . . . . . . . . . . . . . . . . . . . . vi

Background . . . . . . . . . . . . . . . . . . . . . 1

Assumptions . . . . . . . . . . . . . . . . . . . . . . 1

Procedure . . . . . . . . . . . . . . . . . . . . . . 3

Hazard Growth . . . . . . . . . . . . . . . . . . . . 4 4

Impact of Emergency Smoke Removal . . . . . . . . . . . . . . . 5

Response of Automatic Fire Sprinklers . . . . . . . . . . . . . . . . 6

Operation of Smoke Detectors . . . . . . . . . . . . . . . . . 7

Emergency Egress of Visitors . . . . . . . . . . . . . . . . . 7

Emergency Egress from the Memorial Arch . . . . . . . . . . . . . . 7

Analysis . . . . . . . . . . . . . . . . . . . . . 9 9

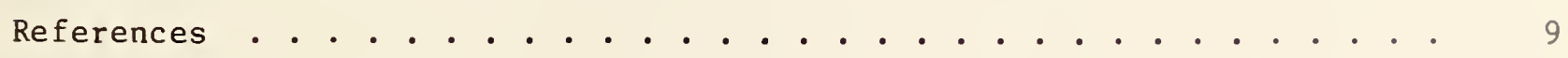

Appendix A . . . . . . . . . . . . . . . . . . . . . . . . . A-1

Appendix B . . . . . . . . . . . . . . . . . . . . . . . . . . . $^{\circ}$. 1 
Figure 1. Facility Floor Plan . . . . . . . . . . . . . . 10

Figure 2. "Semi-Universal Fire Curve" . . . . . . . . . . . . . . . . 11

Figure 3. Fire Environment . . . . . . . . . . . . . . . . 12

Figure 4. Fire Conditions . . . . . . . . . . . . . . . . 13

Figure 5. Sprinkler Response . . . . . . . . . . . . . . . 14

Figure 6. Normally Expected Egress Capacity . . . . . . . . . . . . 15

Figure 7. Optimum Egress Capacity . . . . . . . . . . . . . . 16 


\section{LIST OF TABLES}

$\underline{\text { Page }}$

Table 1. Time to Development of Critical Conditions for Typical

Fire Safety Arrangements . . . . . . . . . . . . . . .

Table 2. Calculated Number of Persons Who Can Be Evacuated Prior to Advent of Firest Critical Condition Shown in Table 1 . . .

Table of Appendix B . . . . . . . . . . . . . . . . . . . . 


\section{FOREWARD}

This report discusses the application of specific fire safety features and their impact on visitor safety. It is the product of a unique effort in intergovernmental cooperation. The report demonstrates the direct benefits of the National Bureau of Standards, Center for Fire Research program as implemented at specific facilities.

We are especially pleased with this combined effort which was aimed at utilizing these concepts. In particular, this information has been useful to National Park Service management for application at Jefferson National Expansion Memorial (JNEM). The result is a better understanding of both the technical research and of its direct, practical benefits.

Because of this joint effort, the National Park Service will be able to safely accommodate additional visitors at JNLM for relatively low additional costs. This permits the service to apply fire safety features in the most cost-effective manner with a clear assurance of their effectiveness.

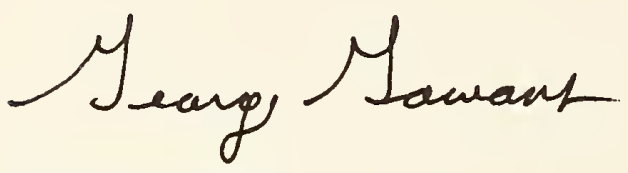

George Gowans

Chief, Engineering and Safety

Services Division

National Park Service

washington, D.C. 20013-7127

March 1, 1985 
Jefferson National Memorial Historical Site

Analysis of Impact of Fire Safety Features

\section{Background}

This analysis has been conducted by staff members of the National Bureau of Standards as part of the ongoing project to develop improved fire safety evaluation approaches for the National Dark Service. The study at the Jefferson National Memorial Historical Site was undertaken both as a feasibility study to assist the National Bureau of Standards in appraising practicality of analytical approaches, and as assistance to the National Park Service in their ongoing efforts to provide effective fire safety in an efficient manner.

The approach used in this analysis consisted of application of fire dynamics calculation methods to predict the rate of development of fire Droducts (smoke and hot gases), the impact of those products within the facility, the relationship of such fire development to the emergency evacuation of visitors, and the response and operation of fire detection and fire protection systems.

Figure 1 is a floor plan of the museum and lobby component of the facility. In addition the facility involves the Memorial Arch rising over the space diagrammed in Figure 1. The footings of the arch appear as large triangles in Figure 1. The arch is accessible to visitors. Normal access is through the lobby descending to tram loading stations located approximately two floors lower than the lobby. Emergency egress can be made through the lobby or through alternative exits located on the lobby side of the doors that separate the tram loading area from the lobby. These are located on the ramp descending from the lobby to the tram loading doors. The doors separating the tram loading area from the lobby are located one floor lower and directly beneath the main museum entrance doors.

\section{Assumntions}

The current ability to calculate fire phenomena required several assumptions In some cases the assumptions may differ from the expected situation. In 
these instances, however, a conservative engineering position was taken to increase the likelihood that the predictions developed are on the safe side. The principal assumptions made were:

1. A severe fire occurs in the museum area. The hypothesized fire exceeds that likely from the fixed exhibits. It represents the maximum burning rate that might occur during an exhibit unpacking and construction operation which involves packing material, pallets, and other similiar loose combustibles in addition to a significant quantity of exhibit materials. To simulate this condition, a fire curve developed by Cooper [1] was used. This curve, which Cooper has named "a semi-universal fire curve" represents a rapidly growing fire based on a compilation of fire test data. This curve is shown in Figure 2.

2. The fire generates smoke and hot gases which rise in a relatively narrow plume towards the celling. Air is entrained into the plume as it rises increasing its volume but decreasing its temperature. When the plume reaches the ceiling it spreads like an impacting fluid jet forming a smoke layer. As the fire progresses this reasonably homogeneous smoke layer descends towards the floor. The air below the layer remains at roughly room temperature and is relatively free of smoke. As the temperature of the smoke layer increases, thermal heat radiation will be transmitted towards the floor, heating objects below the smoke layer. Figure 3 shows a schematic diagram of the fire environment. The general correctness of this assumption has been repeatedly demonstrated in tests and experiments.

3. The smoke produced is assumed to be both dense and intolerable. The density and toxicity of the smoke will be a function of the specific material involved in a fire and may actually be tolerable to some degree or not as dense as assumed in these calculations. The actual condition however is difficult to access and this assumption is therefore appropriate to maintain a conservatively safe calculation.

4. The ceiling is smooth. Actually the ceiling is only semi-smooth with concentric baffles in the museum area and coffered areas in the 1obby. The assumption of smoothness impacts on the prediction of temperature and the response of temperature actuated devices. The actual ceiling configurations provide greater heat transfer surfaces than assumed in the preditions. 
As a result the predicted average smoke layer temperature will be somewhat higher than that which would actually occur given any particular fire incident. The channelization produced by the baffles, however, would have the reverse effect in the space between the baffles directly over the fire and would likely cause heat responsive devices between the baffles to react faster than predicted.

5. Fire protection improvements will be made in the areas not open to the public and in the souvenir and book sales area to prevent fire intrusion from such spaces into visitor spaces. The most likely means of providing this assurance is through the installation of automatic sprinkler protection through these areas, though other methods such as installation of fire resistive compartmentation can also be effective.

6. The smoke control system which now draws supply air from locations near the ceiling can be converted to provide only floor level supply air from outside the building, when operating in the smoke control mode.

The cost of the fire protection improvements and the modifications to the smoke control system have not been appraised. The potential effectiveness of the modified smoke control system is examined in the analysis.

The impact of a fire developing in a non-public space and entering the museum or lobby area is beyond the scope of this analysis. Experience would indicate that there is sufficient combustible material in these spaces to support a "large" fire. If such a fire were to develop in a non public space and then enter the public space at an advanced stage the time available for safe egress would be very short. This assumes that effective egress does not begin until the fire enters the public space. Experience from other fires indicates that this may well occur.

\section{$\underline{\text { Procedure }}$}

The following seven step process was undertaken:

a. Prediction of the growth of hazardous conditions in the public spaces of the museum and the adjacent lobby. 
b. Prediction of the impact of emergency smoke removal if the system were made effective.

c. Prediction of the response of smoke detectors in the public spaces, if provided.

d. Prediction of the response of automatic fire sprinklers in the public spaces, if provided.

e. The predicted egress capabilities if normally expected egress occurs.

f. The predicted egress capabilities if optimum egress management could be obtained.

g. Evaluation of egress potentials for persons in the arch.

In addition to the above analyses a table has been prepared relating the fire protection system as it now exists and as it might be modified to its impact on the ability of visitors to exit before the onset of a hazardous condition.

\section{Hazard Growth}

In this analysis hazard growth is considered to be the increase in the hot gas temperatures in the smoke layer and the descent of this hot, obscuring, toxic layer from the ceiling towards the occupied spaces of the building. The assumptions considered critical for this analysis were:

a. The ceiling lighting system can be obscured when the smoke layer depth is about one foot.

b. Egress through the main doors at the top of the ramps will become difficult when the smoke layer descends approximately four feet below the ceiling.

c. Egress from the rear doors will become difficult when the smoke layer descends approximately 10 feet below the ceiling. 
d. The evacuating occupants will sense objectionable heat from thermal radiation when the smoke layer reaches approximately $200^{\circ} \mathrm{F}$, provided it is still above their heads.

e. Anyone left in the building will be physically harmed by heat radiation from the smoke layer if its temperature reaches about $400^{\circ} \mathrm{F}$, even if it is still above their heads.

The semi-universal fire described in Figure 2 was used as the input to the Available Safe Egress Time fire growth model (ASET) [2] developed by NBS. In applying this model it was assumed that $35 \%$ of the fire energy would be directly radiated from the flame and $90 \%$ of the total energy would be transferred to walls, floors and ceilings. These figures are considered reasonable and conservative based on limited experimentation that has been conducted by NBS. The results of these calculations are plotted in Figure 4. This model predicts one-foot smoke layer depth that could obscure light in 5 minutes, a four-foot layer making exit from the main doors difficult in 11 minutes, and a smoke layer that had a depth of 10 feet in approximately 17 minutes. It also indicates that the temperature in the hot gases would rise to $200^{\circ} \mathrm{F}$ in about 13 minutes and to $400^{\circ} \mathrm{F}$ in 17 minutes. The basic heat transfer calculations involved are shown in Appendix A.

\section{Impact of Emergency Smoke Removal}

A second series of calculations also plotted in Figure 4 were made to determine the impact of a smoke removal system brought into service at approximately the time smoke descended to 1 foot level. Two separate calculations were made. The first based on effective smoke removal of 20,000 cfm (cubic feet per minute); the second on the basis of effective smoke removal of $40,000 \mathrm{cfm}$. It is expected that the removal of these gases would have a minor effect on the gas temperature but would significantly effect the rate of smoke layer descent. Using the ASET model the descent of the smoke layer indicates that it would reach a 4 foot depth (impacting on the main door egress) at approximately 15 minutes with the 20,000 cfm smoke removal capab111ty and 17 minutes with the 40,000 cfm removal. Similarly a 10 foot depth would be reached at approximately 19 minutes given 20,000 cfm smoke removal and 22 minutes given $40,000 \mathrm{cfm}$. 
Recently developed methods of calculating the potential thermal ceiling jet of a fire and the response of sprinkler heads to such a jet were used to determine the impact of several different arrangements and styles of sprinklers. Also within the past several years an important hardware advance has been made in sprinkler heads. Sprinklers are now available in different ranges of responsiveness to their rated temperature. This difference is included in a factor called "Response Time Index" (RTI). Those sprinkler heads with low thermal heat sinks (and therefore rapid response) have low response time indices. Some have reached the market with indicies in the range of approximately 20. The traditional sprinkler heads have indicies that range from about 100 to 300. Figure 5 shows the results of calculations based on the same fire conditions used to predict hazard growth. Calculations show that the range of sprinkler response can vary from approximately 3 minutes to as high as 6 minutes depending on the sprinkler head and the spacing selected. Sprinkler response is used here to indicate the time elapsed between the beginning of the fire and the opening of the first sprinkler head. The hazard development curves shown in Figure 4 are marked to show the range of hazardous conditions that would be predicted at the time of the operation of the sprinkler heads. The sprinklers are predicted to operate before the average upper layer temperature reaches the sprinkler head setting. This is because the sprinkler will be heated by a hot ceiling jet. See Figure 3. In view of the openness of the museum and the low probability that a fire would involve concealed spaces, sprinklers would be highly effective. It can be expected that the fire would be promptly terminated or brought to a very low energy production level upon the operation of one or more sprinkler heads. The action of the flow from the sprinkler heads would however, pull some of the smoke from the ceiling level to the floor level. This recirculation would take place in some unpredictable but relatively brief period of time. Calculation of the potential toxic level and obscuration from such recirculation (See Appendix B) indicate that the recirculated smoke would be well below toxic hazard levels but would decrease occupant visibility. If the sprinklers used were of the fast response type the reduction in vision would be very modest. If the sprinklers were of the conventional operating type the obscuration would eventually reduce visibility to less than $30 \mathrm{ft}$, even if lighting were provided below the smoke levels. 
The estimate of the operation of smoke detectors is based on the calculation procedure used for the sprinkler heads. The smoke detectors were treated as a response device having a zero response time index and a temperature rating of about $85^{\circ} \mathrm{F}$. On this basis a smoke detector on a reasonable spacing near the ceiling would be expected to operate in approximately 1 minute from the initiation of the fire. (See Appendix B for calculations and references)

\section{Emergency Egress of Visitors}

Egress capabilities were based on data developed by Fruin[3] and Predtechenski[4]. Appendix B provides the basic calculation data used. Two different calculations were made as follows:

a. Figure 6 shows the evacuation time based on the exits available if it is assumed that many persons will move from the museum through the large passageway into the lobby and will not return to the museum even if the rear doors of the museum are opened. This is the type of evacuation that would be expected if no special evacuation procedures were implemented by Park Service personnel.

b. The second arrangement, shown in Figure 7, plots the improvement in egress capability that would occur if all exits were used in an optimum manner. This would possibly involve ushering persons who had moved from the museum to the lobby back into the museum to use the rear exits. If all exits were used there would be approximately a $20 \%$ decrease in time required for all persons to leave the building. If some of the exits become blocked or otherwise unused, the egress time advantage will be less significant.

Emergency Egress from the Memorial Arch

In case of fire, emergency egress from the arch can be accomplished by either transporting the persons at the top of the arch using the tram or by descending the stairs located in each arm of the arch. In view of the ever present possibility of electrical interruption, it is expected that normal 
precaution would lead towards walking from the arch using the stairs. The author descended these stairways at a comfortable pace. In this single exercise the descent time was 15 minutes. Given the possibility of as many as 200 persons at the top of the arch and the varying conditions and capabilities of such persons a descent time of 15 to 30 minutes is probably the best estimate that can be made. Estimates made on evacuating as many as 200 persons using the tram result in approximately the same amount of time.

It can be seen from examining Figure 4 and Table 1, a way in which the lobby portion can be safeguarded for a sufficient period of time to allow emergency egress through the lobby is through the use of automatic sprinklers.

An alternative however is available. This alternative is based on using the existing arch ventilation system to develop a smoke proofed arrangement for each of the legs of the arch and the emergency egress path from the arch to the outside. Architecturally this would require providing at least one additional set of doors near the base of the ramp sections descending on each side of the lobby to the tram loading areas. The apparent best location for such doors is near the point where the slope of the ramp is interrupted and a flat section occurs on the lobby side of the present doors. This will effectively separate the lobby from the ramp discharge arrangements using the emergency exit passageway and stairs located east of this position.

The second item necessary to achieve smoke proofing of the arch exit arrangement involves adjusting the controls on the present HVAC system for the arch. It will also involve the installation of dampers or other means to cut off the final section of the HVAC system that provides supply air into the observation platform and machine room at the top of the arch. The emergency system needs to be controlled to provide a positive pressure (preferably in the range of approximately 0.1 inches of water) at the dividing lines between the exit path and the lobby and between the observation platform and the top of each of the legs. In addition, it is important that smoke detection arrangements be provided in the fan plenums to assure that any fire in the filters or machinery within the plenums will cause the fans to shut down and not nump smoke into the arch. Most if not all of the control equipment necessary to accomplish this is incorporated in the existing fan control system. 
An analysis of the preceeding predictions is made in Tables 1 and 2 .

Table 1 relates the predicted available egress time from initial flame to selected critical conditions as the facility now exists and the predicted available egress time that would occur if certain fire protection features were added to the facility.

Table 2 shows the predicted number of persons that can egress through all or a portion of the facility exits in the time available as shown in Table 1. In preparing Table 2 it has been assumed that a fire of the severity shown in Figure 3 would be fully self announcing within 3 minutes of ignition. By that time, the fire would be burning at the rate of 500 kilowatts and would produce a flame threatening to everyone in the building. Therefore, the calculation of egress capacity assumes a 3 minute start-up delay in all situations where the fire safety arrangement does not involve a general smoke detection system. Where the fire safety arrangement involves general coverage of the museum and lobby area with a smoke detection system, the calculation of egress capacity assumes a 1 minute start-up delay in recognition of the early warning provided by detectors.

\section{$\underline{\text { References }}$}

[1]. L.Y. Cooper, "A Mathematical Model for Estimating Available Safe Egress Time in Fires," Fire and Materials, Vol. 6, Nos. 3 and 4, 1982 , pp. 135-144.

[2]. L.Y. Cooper and D.W. Stroup, Calculating Available Safe Egress Time (ASET) - A Computer Program and User's Guide, NBSIR 82-2478, Nat'1 Bureau of Standards (September 1982).

[3]. J.J. Fruin, Pedestrian Planning and Design; Metropolitian Association of Urban Designers and Environmental Planners, Inc., New York, N.Y., 1971.

[4]. V.M. Dredtechenskii and A.I. Milinskii; Planning for Foot Traffic Flow in Buildings; Stroiiat Publishers, Moscow, 1969 (Translated f rom Russian by Amerind Publishing Co. Put. Ltd. New Delhi for the National Bureau of Standards and National Science Foundation, 1978). 


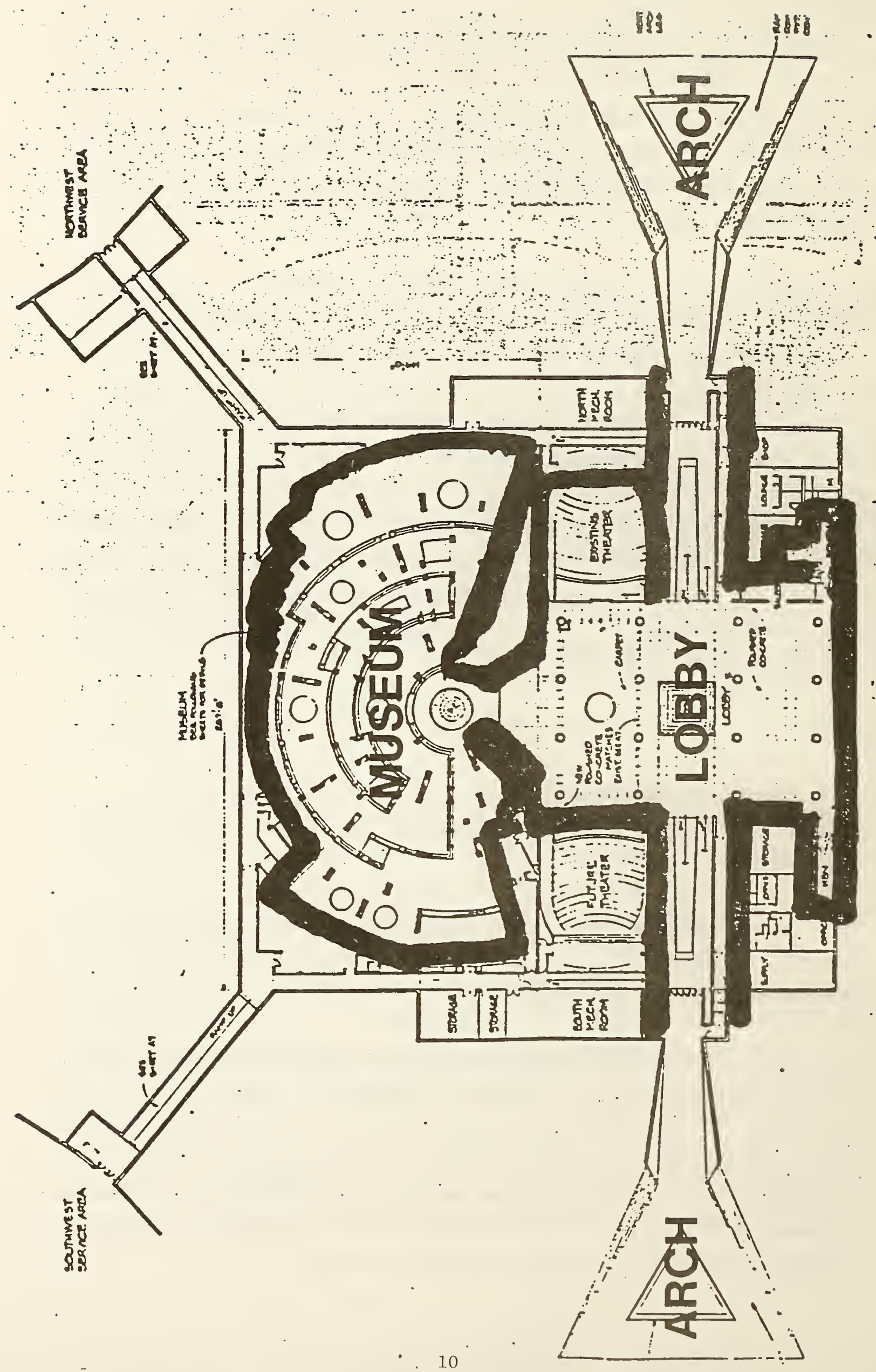

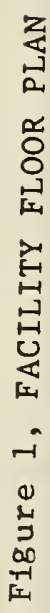



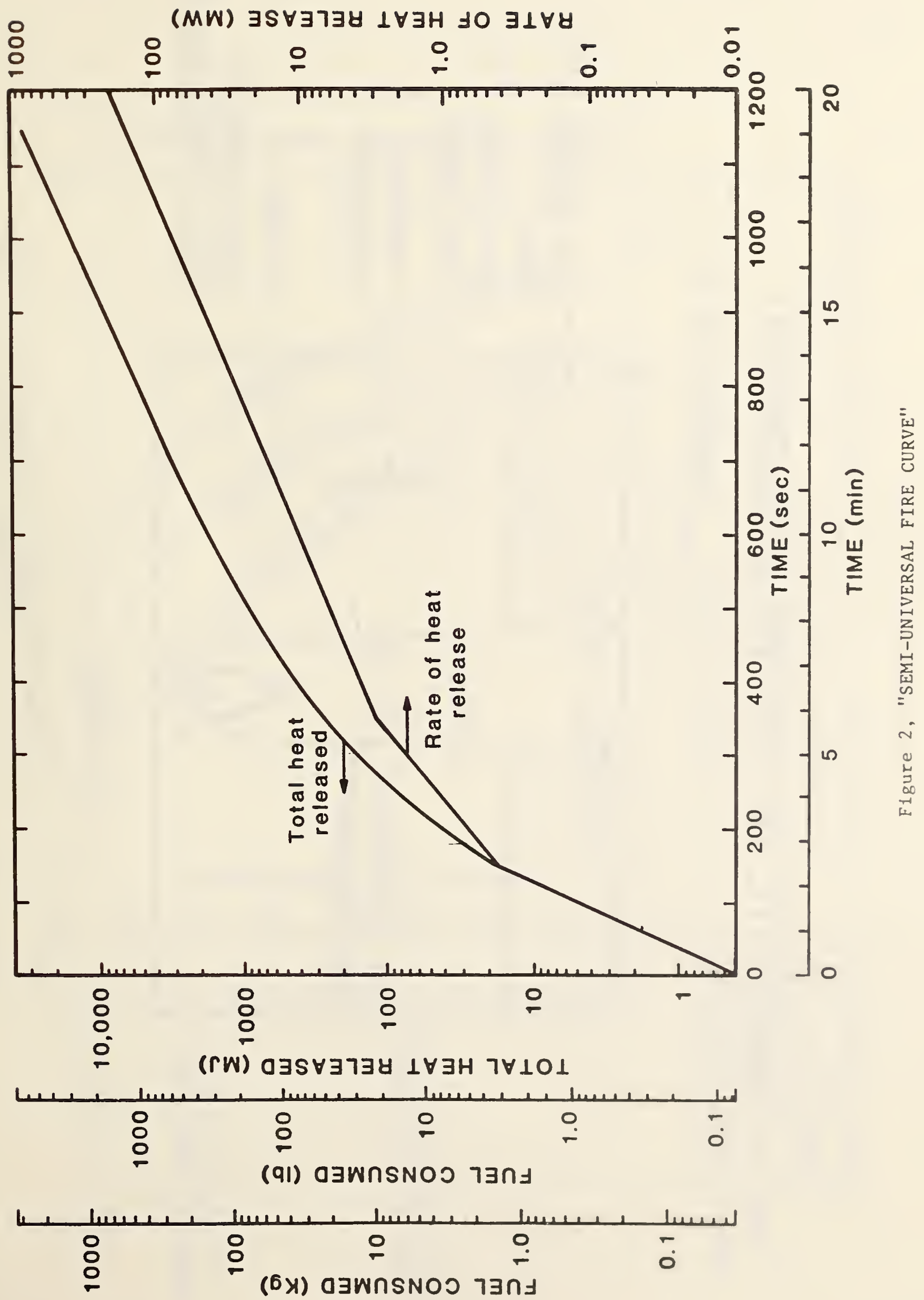


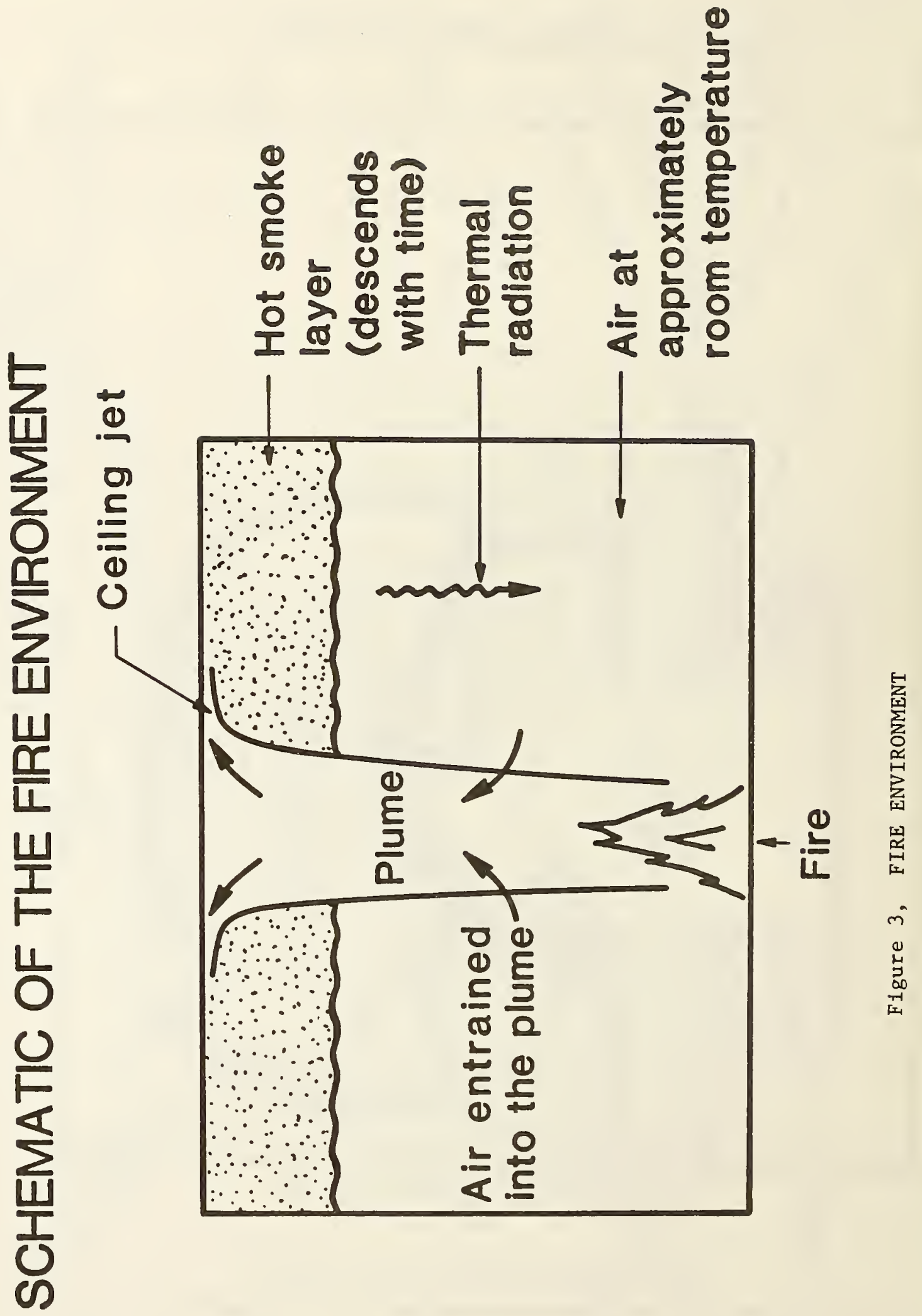




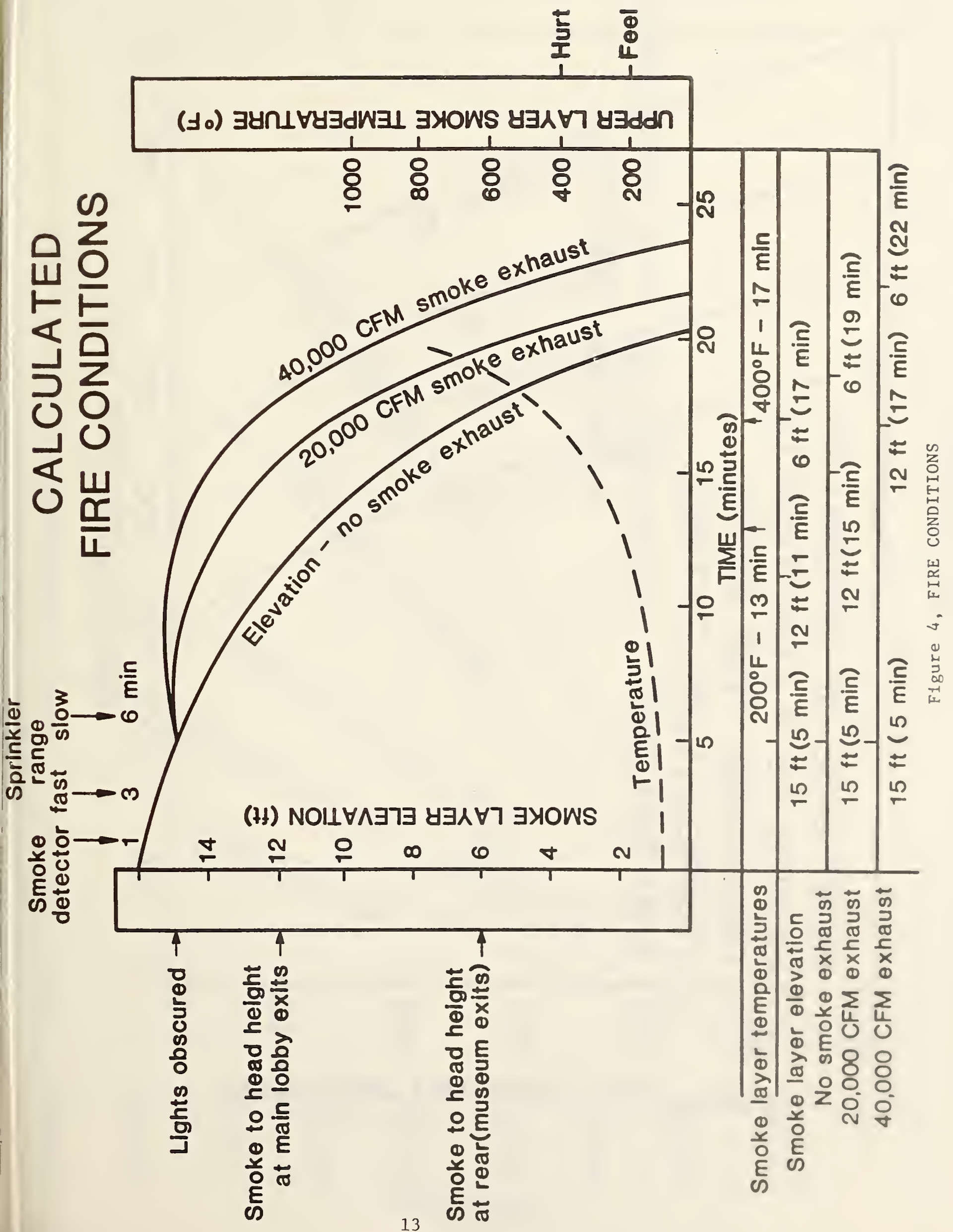




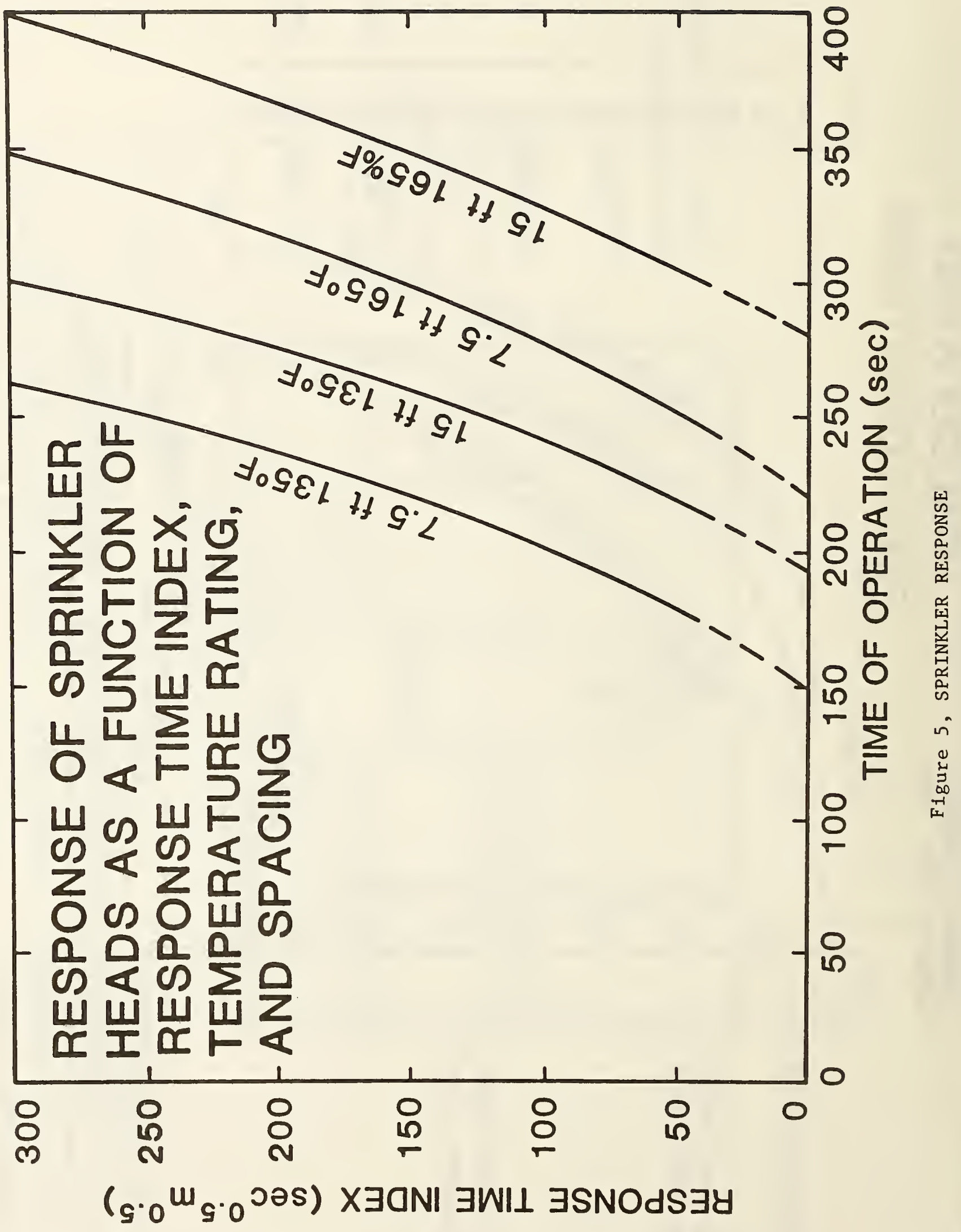




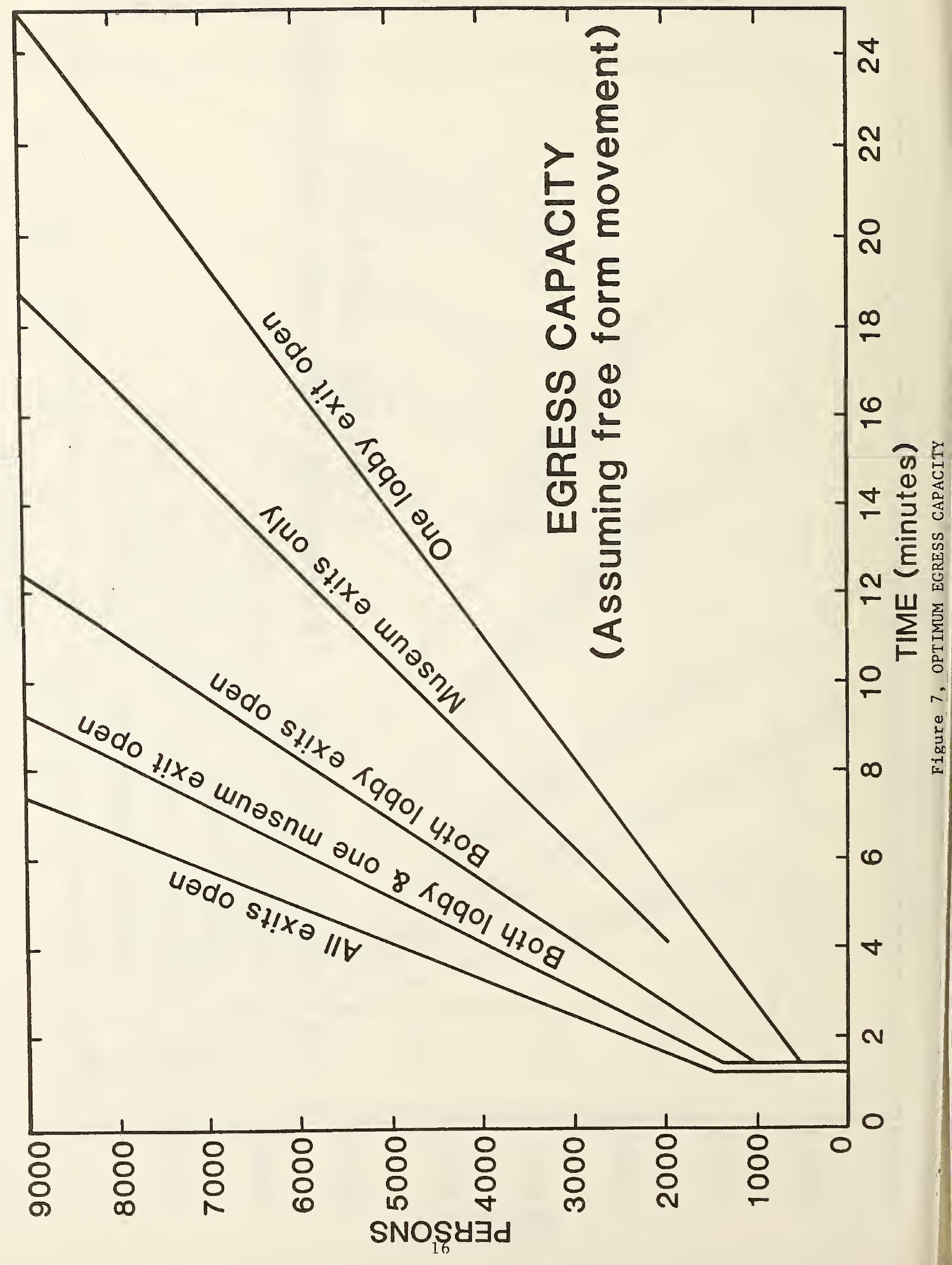




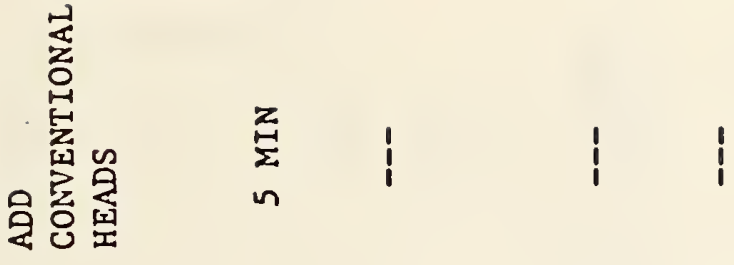

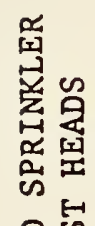

影

密是

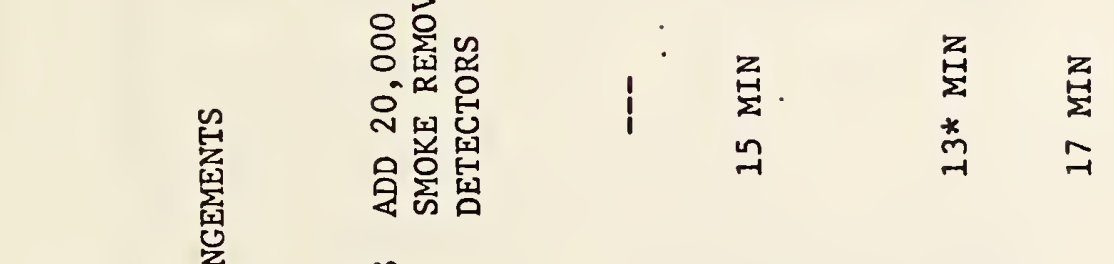

点

జ

号 일

睤舅

叫点

[x

占㠫

总召

星是

$\sum$

四品

空

윕중

鼠瓷

国

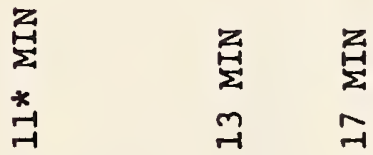

点

岕嘕

留

总总

茎忌

窝

务菖

蛋

*

窑

昆点

$\Rightarrow$ 극

疍

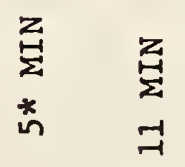

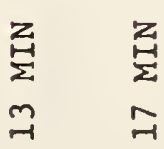

临

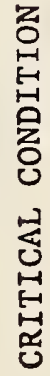

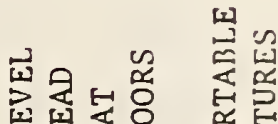

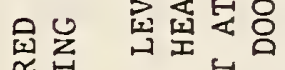

骂峀

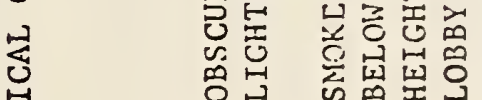

员点焉

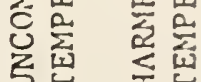

巩

至 


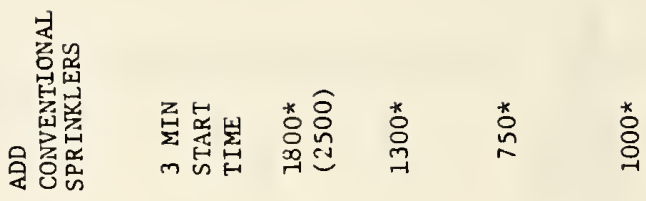

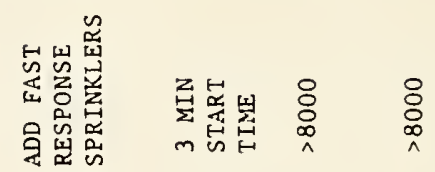

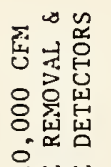

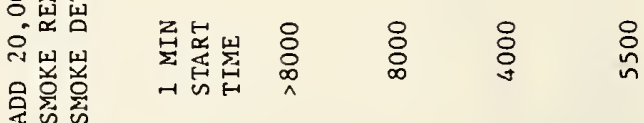

岁

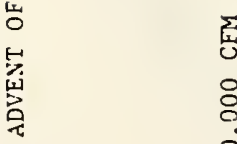

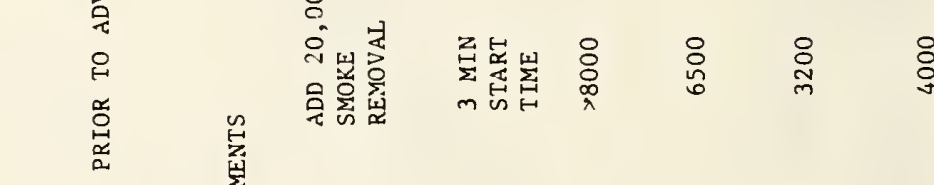

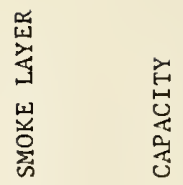

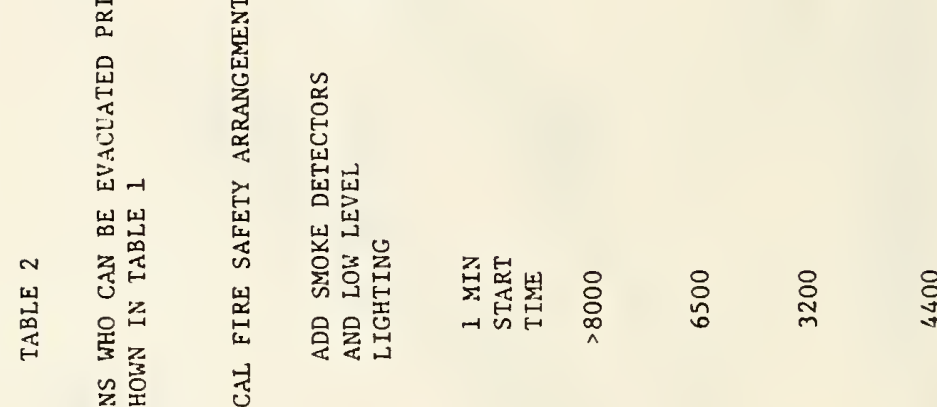

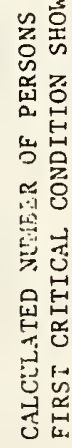

岀

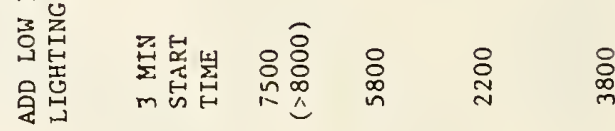

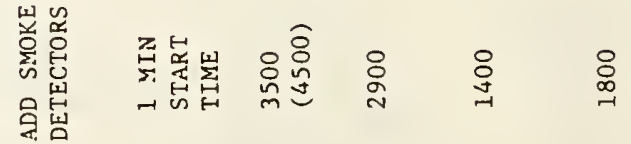

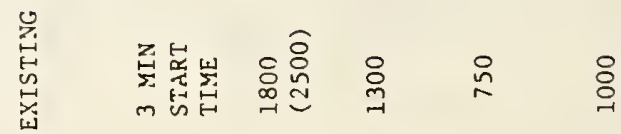


Heat Transfer Related Calculations for the Jefferson National Memorial Historical Site

I. Methodologies

A. Hazard Growth

The Available Safe Egress Time (ASET) computer code was used to calculate fire environment conditions in the Jefferson National Memorial Historical Site. This computer program solves equations, developed by Cooper ${ }^{1}$, to determine the time dependent upper layer thickness and temperature histories. The equations for the dimensionless interface position, $\zeta$, and the upper layer temperature, $\phi$, are

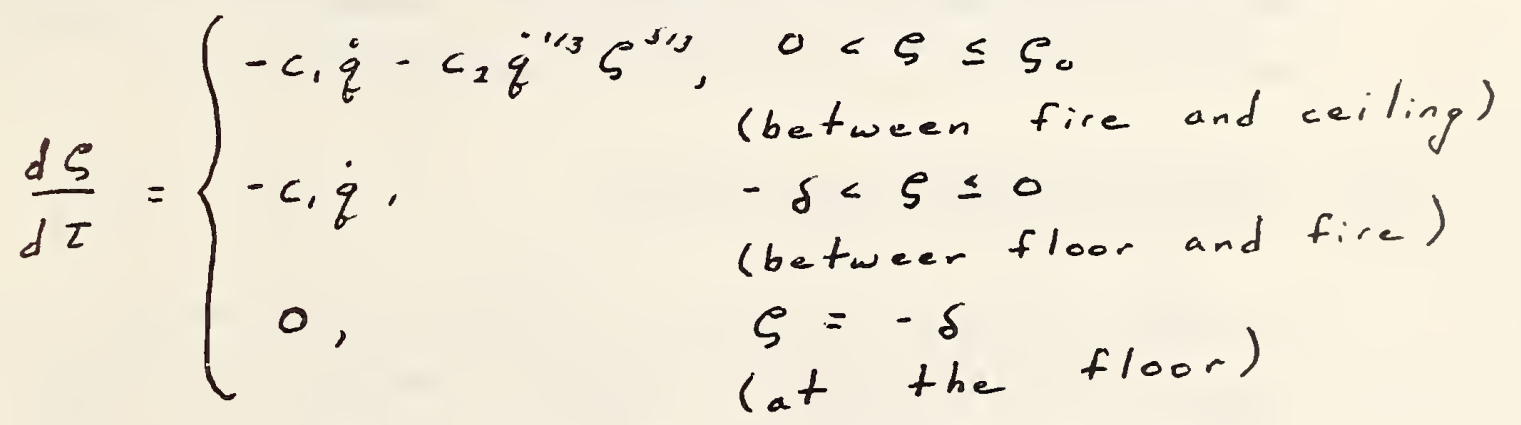

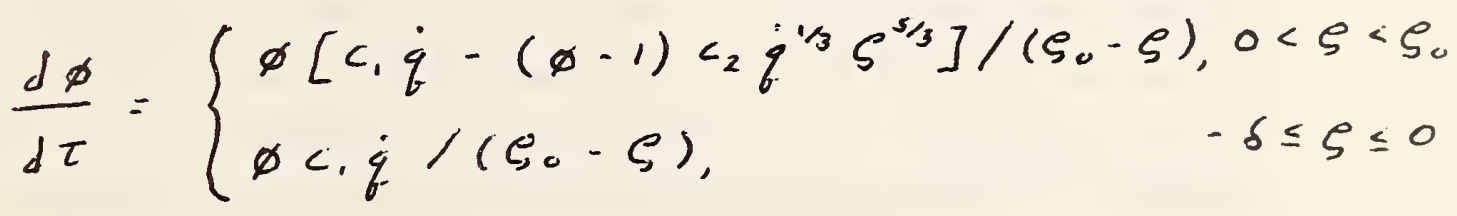

where: $S_{0}=H / L_{c}, \delta=\Delta / L_{c}, \dot{q}=\dot{Q} / \dot{Q}_{c}$,

$$
\begin{aligned}
& c_{1}=\frac{\left(1-\lambda_{c}\right) \dot{Q}_{0} t_{c}}{\rho_{a} c_{p} T_{a} A L_{c}}, \\
& c_{2}=\frac{0.210 t_{c}}{A}\left[\frac{\left(1-\lambda_{r}\right) \dot{Q}_{0} g L_{c}^{2}}{\rho_{a} C_{p} T_{a}}\right]^{1 / 3}
\end{aligned}
$$

The model requires data describing the fire's elevation and energy generation rate along with a description of the enclosure geometry (height and area). The percentage of fire energy radiated from the flame and the percentage of fire energy lost to the walls, floor, and ceiling must also be estimated. 
The semi-universal fire, used as input to the model, is the result of a fit of data, from burn tests on a variety of different types of commodities, to a three-segment, multi-exponential fire growth curve. The fire is initiated from a $10 \mathrm{~kW}(9.8 \mathrm{BTU} / \mathrm{s})$ ignition source. It grows exponentially at a rate characteristic of a fire initiated in a polyurethane mattress with bedding. This early growth rate would be appropriate for use in characterizing the early growth of fire's in upholstered polyurethane cushioning or large assemblies of commodities stacked on pallets. The fire growth rate beyond $400 \mathrm{~kW}$ (379 BTU/s), described in two segments, is similar to that observed for fires initiated in a variety of different types of commodities stacked on pallets. 2 The fire is assumed to be located one foot above the floor. The percentage of fire energy lost by radiation from the flame and the percentage of fire energy transferred to walls, floors and ceilings were assumed to be $35 \%$ and $90 \%$ respectively. The room height and area were $16 \mathrm{ft}$. and $50,516 \mathrm{ft}^{2}$ respectively.

B. Impact of Emergency Smoke Removal

In order to examine the impact of emergency smoke removal, the ASET computer code was adjusted to include a venting term. Since it was expected that the removal of smoke from the upper layer would have minimal affect on the upper layer gas temperature, the venting term was only applied to the interface position equation. The adjusted equations for the dimensionless interface position, $\zeta$, and the upper layer temperature, $\phi$, are

$$
\begin{aligned}
& \frac{d \varphi}{d \tau}=\left\{\begin{array}{lc}
-c_{1} \dot{q}-c_{2} \dot{q}^{1 / 3} \rho^{5 / 3}+V^{*}, & 0<\rho \leq \varphi_{0} \\
-c_{1} \dot{q}+V^{*}, & -\delta<\varphi \leq 0 \\
0, & \rho=-\delta
\end{array}\right. \\
& \frac{d \phi}{d \tau}= \begin{cases}\phi\left[c_{1} \dot{q}-(\phi-1) c_{2} \dot{q}^{1 / 3} \rho^{5 / 3}\right] /\left(\zeta_{0}-\rho\right), & 0<\zeta<\rho_{0} \\
\phi c_{1} \dot{q} /\left(\rho_{0}-\rho\right), & -\delta \leq \zeta \leq 0\end{cases} \\
& \text { where: } S_{0}=H / L_{c}, \delta=\Delta / L_{c}, \dot{q}=\dot{Q} / \dot{Q}_{0} \text {, } \\
& c_{1}=\frac{\left(1-\lambda_{c}\right) \dot{Q}_{0} t_{c}}{\rho_{a} c_{p} T_{a} A L_{c}}, \quad c_{2}=\frac{0.210 t_{c}}{A}\left[\frac{\left(1-\lambda_{r}\right) \dot{Q}_{0} g L_{c}^{2}}{\rho_{a} C_{p} T_{a}}\right]^{1 / 3}
\end{aligned}
$$


This change, while not a true representation of the venting phenomenon, was considered accurate enough for the purpose intended here. The altered model required the same inputs as the standard ASET version with the addition of a ventilation rate specified in cubic feet per minute (cfm).

C. Response of Automatic Fire Sprinklers

The response of automatic fire sprinklers to fire conditions, in an enclosure, is a function of the ceiling jet temperature and velocity histories and the thermal response characteristics of the sensing element.

Correlations of ceiling jet temperatures and velocities, obtained from the study of steady fires by Alpert ${ }^{3}$, were used to predict the temperature and velocity histories in the ceiling jet flow. The dimensionless forms of the equations for maximum temperature rise, $\Delta \mathrm{T}_{\mathrm{m}}^{*}$, and velocity, $\mathrm{U}_{\mathrm{m}}^{*}$, are

$$
\begin{gathered}
\Delta T_{m}^{*}= \begin{cases}6.18, \quad & r / H \leq 0.18 \\
1.97(r / H)^{-2 / 3}, & r / H>0.18\end{cases} \\
U_{m}^{*}= \begin{cases}3.16, \quad r / H \leq 0.15 \\
0.65(r / H)^{-5 / 6} & r / H>0.15\end{cases} \\
\begin{array}{c}
\Delta T_{m}^{*}=\Delta T_{m}\left(C_{p}^{2} \rho_{a}^{2} g H^{5} / T_{a} \dot{Q}_{c}^{2}\right)^{1 / 3} \\
U_{m}^{*}=U_{m}\left(C_{p} T_{a} \rho_{a} H / g \dot{Q}_{c}\right)^{1 / 3}
\end{array}
\end{gathered}
$$

Once the ceiling jet temperature and velocity profiles were calculated, the response of a sprinkler, at a given radial location, was calculated using the equation

$$
\frac{d\left(\Delta T_{L}\right)}{d t}=\frac{U_{m}^{1 / 2}}{R T I}\left(\Delta T_{g}-\Delta T_{L}\right)
$$


where $\Delta T_{I}$ is the excess temperature of the link above its initial temperature, $\Delta \mathrm{T}_{\mathrm{g}}$ is the excess temperature of the gas surrounding the link, and RTI is the response time index for the sprinkler. 4

D. Celling Jet Temperatures

Ceiling jet temperatures calculated by the methods proposed by Alpert ${ }^{3}$ vary with the time into the fire and the radial distance from the fire axis. The calculated ceiling jet temperatures for the museum or lobby areas in case of a fire following the course plotted in Figure 2 are:

\begin{tabular}{|c|c|c|c|c|c|}
\hline \multirow{2}{*}{$\begin{array}{l}\text { Time } \\
\text { into } \\
\text { Fire }\end{array}$} & \multirow{2}{*}{$\begin{array}{l}\text { Burning } \\
\text { Rate } \\
\text { Btu/sec) }\end{array}$} & \multicolumn{4}{|c|}{$\begin{array}{l}\text { Ceiling Jet Temperatures } \\
\text { Radial Distance From Fire Axis }\end{array}$} \\
\hline & & $1 \mathrm{ft}$. & $7.5 \mathrm{ft}$. & $15 \mathrm{ft}$ & $30 \mathrm{ft}$. \\
\hline $1 \mathrm{~min}$. & 50 & $115^{\circ} \mathrm{F}$ & $90^{\circ} \mathrm{F}$ & $83^{\circ} \mathrm{F}$ & $78^{\circ} \mathrm{F}$ \\
\hline 3 min. & 800 & $350^{\circ} \mathrm{F}$ & $210^{\circ} \mathrm{F}$ & $157^{\circ} \mathrm{F}$ & \\
\hline 6 min. & 9000 & $1500^{\circ} \mathrm{F}$ & $700^{\circ} \mathrm{F}$ & $500^{\circ} \mathrm{F}$ & \\
\hline
\end{tabular}


E. Estimation of Detector Operating Time

Correlations developed by Heskestad ${ }^{5}$ and Evans ${ }^{4}$ have demonstrated that a reasonable relationship can be drawn between the ceiling jet temperature from an open flaming fire and the response of a smoke detector to the particles in that hot jet. For modern smoke detectors the operation can be expected when the jet temperature rises $3^{\circ} \mathrm{F}$ to $13^{\circ} \mathrm{F}$. For these calculations a conservative value of $15^{\circ} \mathrm{F}$ rise over a $70^{\circ} \mathrm{F}$ room temperature was used.

F. Constituency of the Smoke

The constituency of the smoke is derived from the amount of material burned (from Figure 2 and the level of the smoke layer (from Figure 4). The procedure is as follows:

a. The fuel is assumed to be 80 percent wood or similar natural materials and 20 percent synthetic materials.

b. The products produced by burning the fuel will develop a toxic level equivalent to one that is lethal to 50 percent of test animals exposed to that concentration for 30 minutes when the mass burned divided by the volume involved is approximately 40 grams per cubic meter. (0.0025 1bs. per cubic feet)

c. Approximately 3 percent of the burned material will be distributed through the smoke as light obscuring aerosols.

d. Toxicity is determined from the formula:

$$
Y_{T}=\frac{M}{d \cdot A \cdot \overline{E C}_{50}}
$$


where:

$\mathrm{Y}_{\mathrm{T}}=$ Toxicity factor $=$ Multiples of $\overline{\mathrm{LC}}_{50}$

$M=$ Mass burned $(g)$

$d=$ Depth of smoke layer (m)

$A=$ Area of space $\left(\mathrm{m}^{2}\right)$

$\overline{\mathrm{LC}}_{50}=$ Toxic concentration to produce a lethal dose to 50 percent of the exposed animals exposed for that concentration for 30 minutes $\left(\mathrm{g} / \mathrm{m}^{3}\right)$

e. Visibility through the smoke layer is evaluated by the formula from Rasbash ${ }^{6}$.

$$
v_{s}=1.4 D_{0}^{-0.767}
$$

where:

$$
\begin{aligned}
& \mathrm{V}_{\mathrm{S}}=\text { Distance of sight }(\mathrm{m}) \\
& \mathrm{D}_{\mathrm{O}}=\text { Optical density per meter } \\
& \text { and } \mathrm{D}_{\mathrm{O}}=3.5 \frac{\mathrm{Y}_{\mathrm{S}} \mathrm{M}}{\mathrm{V}}
\end{aligned}
$$

where:

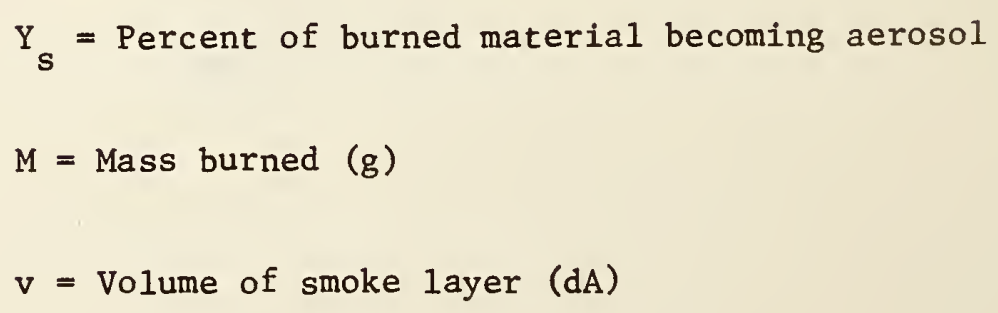


f. For this analysis the fuel involved in the fire is considered to be $80 \%$ natural materials (wood, paper, and similar materials) and $20 \%$ synthetic (primarily plastics.) The $\overline{\mathrm{LC}}_{50}$ is $(0.4 \mathrm{~g}$ per cubic meter $\left(0.00171\right.$ bs per cubic feet). The $Y_{s}$ is 3 percent.

g. Using the preceding data and formulae the constituency of the smoke layer at various times into the fire is:

time

$1 \mathrm{~min}$

3 min

5 min

6 min

11 min

$\mathrm{Y}_{\mathrm{T}}\left(\mathrm{xLC}_{50}\right)$
0.0125
0.05
0.21
0.35
0.75$$
\mathrm{Y}_{\mathrm{T}}\left(\overline{\mathrm{xC}}_{50}\right)
$$$$
0.05
$$

Vision in smoke layer

44 feet

17 feet

6 feet

3 feet

2 feet

h. If the operation of a sprinkler head promptly extinguishes the fire but also churns the smoke through the volume of the museum and lobby the value of $\mathrm{Y}_{\mathrm{T}}$ would be 0.0014 (ie less than $1 \%$ of the $\mathrm{LC}_{50}$ ) if the fire is terminated at $3 \mathrm{mins}$ or $0.02\left(2 \%\right.$ of $\left.\mathrm{LC}_{50}\right)$ if the fire is terminated at 6 mins.

i. When a sprinkler head operates it adds water vapor to the atmosphere. Currently we have no way to calculate the impact of the water vapor fog on visibility. The portion of the obscuration presented by the smoke can however be estimated as $90 \mathrm{ft}$. for the matter released in the first 3 mins. of the fire and $28 \mathrm{ft}$ for the matter released in the first 6 mins. Actual visibility would be something less due to the added water vapor. 
II. References

[1]. L.Y. Cooper, "A Mathematical Model for Estimating Available Safe Egress Time in Fires," Fire and Materials, Vo1. 6, Nos. 3 and 4, 1982, pp. 135-144.

[2]. L.Y. Cooper, and D.W. Stroup, Calculating Avallable Safe Egress Time (ASET) - A Computer Program and User's Guide, NBSIR 82-2478, Nat'1 Bureau of Standards (September 1982).

[3]. R.L. Alpert, "Calculation of Response Time of Ceiling - Mounted Fire Detectors," Fire Technology, 8, 1972, pp. 181-195.

[4]. D.D. Evans, Thermal Actuation of Extinguishing Systems, NBSIR in process.

[5]. G. Heskestad and M.A. Delichatsios, Environment of Fire DetectorsPhase I: Effect of Fire Size, Ceiling Height and Material, Volume IIAnalysis, FMRC Serial No. 22427, Factory Mutual Research Corporation, 1977.

[6]. D.J. Rasbash, "Smoke and Toxic Products Produced at Fires", Trans. J. Plastic Inst., Jan. 1967, p. 55. 


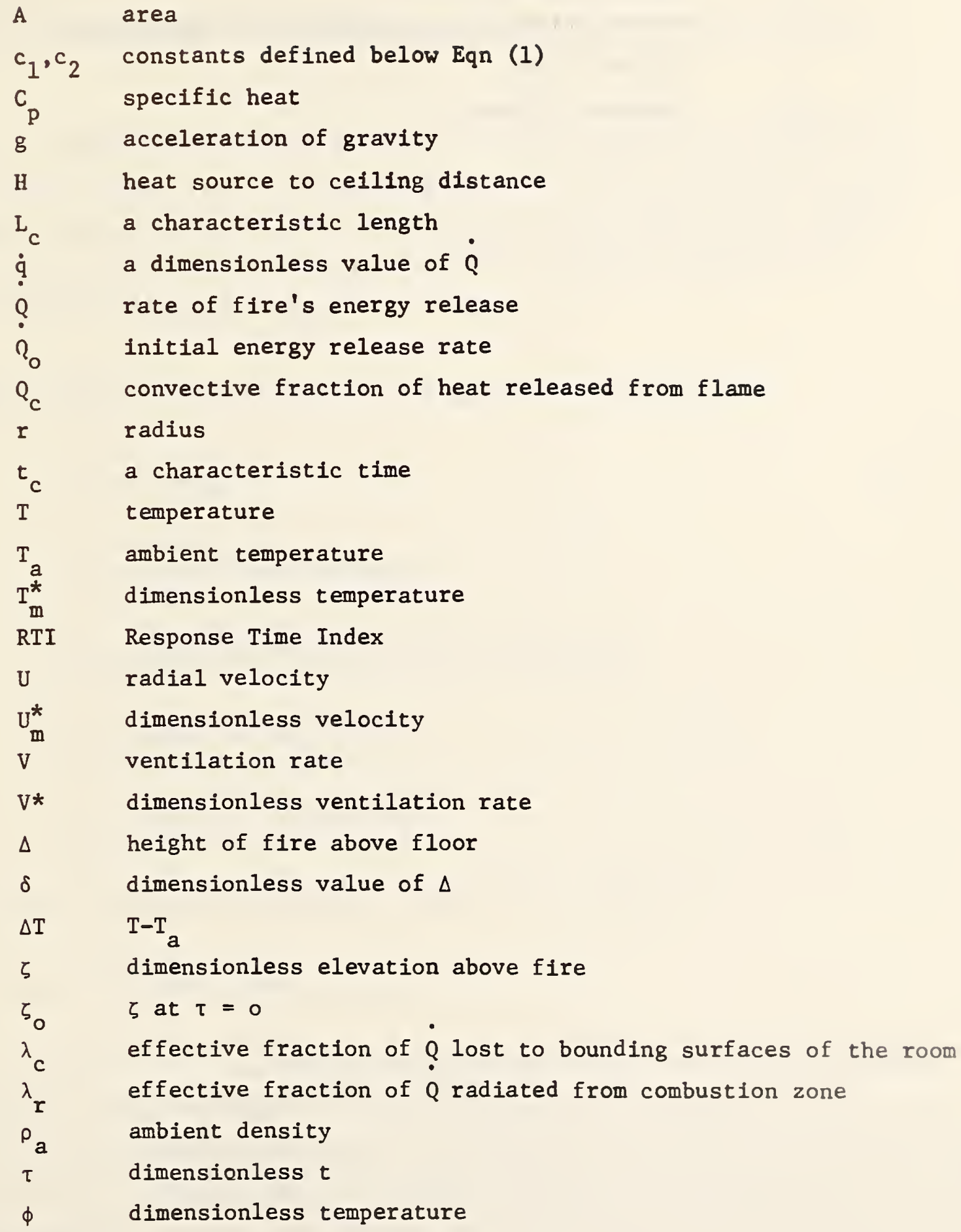


L sensing element, link maximum value at given radius for celling jet inftial value constant pressure 
Egress Calculations for the Jefferson National Memorial Historical Site

The egress capabilities of the Jefferson National Memorlal Historical Site were analyzed using two different scenarios. The first would be the result of normally expected egress from the structure. The other would require optimum use of the egress facilities possibly involving redirection of people movement by NPS personnel.

The basic formula used to calculate the required egress time is:

$$
E=\frac{P}{R}=\frac{P}{N \times B}
$$

where: $\quad P=$ Population of Structure

$$
\begin{aligned}
& \mathbf{R}=\text { Pedestrian Flow Rate out of Structure } \\
& \mathrm{N}=\text { Number of exit doors } \\
& B=\text { Capacity of each Door }
\end{aligned}
$$

The data used in the calculations is presented in Table $1 b$.

\section{Normally Expected Egress}

In this scenario, it is assumed that many persons will move from the museum through the large passageway into the lobby and will not return even if the rear doors of the museum are opened. Furthermore, the last people exiting the muscum portion of the structure leave the various openings at the same time. The flow would be unevenly divided, and a backup would develop at the lobby exits. As a result, people would still be waiting, in the lobby, to exit the structure while the back exits, from the museum, were empty. The procedure used to calculate the required egress time for this situation is presented below: 
1. Calculate the flow rate of people through the passageway using the formula:

$$
R_{p}=\frac{W_{0}}{A}
$$

where:

$$
\begin{aligned}
& R_{p}=\text { Flow rate for passageway } \\
& W_{0}=\text { Width of passageway opening }
\end{aligned}
$$

$$
\text { A = Required exit width for openings with no doors }
$$

2. Using $R_{p}$ from equation (2), calculate the flow rate of persons through all openings in the museum

$$
R_{r}=\left(N_{m} \times B\right)+R_{p}
$$

where: $\quad R_{r}=$ Total flow rate of persons leaving museum

$$
\begin{aligned}
& N_{m}=\text { Number of exits from museum (excluding passageway) } \\
& B=\text { Capacity of an exit with free swinging door }
\end{aligned}
$$

3. The time required to empty the museum is determined using the basic formula

$$
E_{m}=\frac{P_{m}}{R_{r}}
$$

where: $\quad E_{m}=$ Required egress time for museum

$$
\mathrm{P}_{\mathrm{m}}=\text { Population of museum }
$$

4. Use the egress time for the museum to determine the number of people who move from the museum to the lobby

$$
P=E_{m} \times \frac{W_{0}}{A}
$$

where: $\quad P$ = Number of people who move from museum to lobby 
5. Finally, calculate the time required to empty the lobby

$$
E_{L}=\frac{P_{L}+P}{N_{L} \times B}
$$

where:

$$
\begin{aligned}
& E_{L}=\text { Required egress time for lobby } \\
& P_{L}=\text { Population of lobby } \\
& N_{L}=\text { Number of exits from lobby }
\end{aligned}
$$

The results of these calculations are shown in Figure 6 .

\section{Optimum Egress Capacity}

In this scenario, it is assumed the people exit the structure in a manner such that the flow is evenly divided among doors. This would require an exit with five doors to carry five times as many people as an exit with one door. Consequently, it is assumed that the last people moving through the various exits leave the building at the same time. This could only be the result of a planned exit system where people are directed to the exit which would release them to the outside in the optimum amount of time. While this may be difficult to achieve in practice, the required egress time for the entire structure may be calculated simply from equation ( 1 ).

$$
E_{s}=\frac{P_{s}}{N_{s} \times B}
$$

where: $\quad E_{S}=$ Required egress time for the entire structure

$$
\begin{aligned}
& P_{S}=\text { Population of the entire structure } \\
& N_{S}=\text { Number of exits from the structure } \\
& B=\text { Capacity of an exit with free swinging door }
\end{aligned}
$$

The results of this calculation for various combinations of open and closed exits are shown in Figure 7. 


\section{Minimum Exit Time}

The required egress time, for the bullding, cannot be less than the time required for the person farthest from an exit to exit the building. The distance farthest from an exit is determined for each case, and a travel time is calculated using the appropriate walking speed. This is shown as the minimum exit time in Figures 6 and 7. 
TABLE 1 of Appendix B

EGRESS DATA

$B=$ Capacity of each door $=60$ persons per minute $\begin{aligned} R_{p}= & \text { Flow rate for passageway }=30 \text { persons per minute per } \\ & \text { foot of width }\end{aligned}$

BD 
NBS-114A (REV. 2-00)

U.S. DEPT, OF COMM

1. PUBLICATION OR

BIBLIOGRAPHIC DATA

SHEET (See in struction s)

REPORT NO NBSIR $84-2897$

2. Performlng Organ. Report Nof 3. Publlcation Date

March 1985

4. TITLE AND SUBTITLE

Jefferson National Memorial Historical Site

Analysis of Impact of Fire Safety Features

5. $A U T H O R(S)$

Harold E. Nelson

6. PERFORMING ORGANIZATION (If joint or other than NBS, see instructions)

7. Contract/Grant No.

NATIONAL BUREAU OF STANDARDS

DEPARTMENT OF COMMERCE

8. Type of Report \& Period Covered

Gaithersburg, MD 20899

9. SPONSORING ORGANIZATION NAME AND COMPLETE ADDRESS (Street, CIty, Stote, ZIP)

National Park Service

Department of Interior

Washington, D.C.

10. SUPPLEMENTARY NOTES

[] Document describes a computer program; SF-185, FIPS Software Summary, is attached.

11. ABSTRACT (A 200-word or less factual summary of most significant information. If document Includes a s/gnifleant bibliography or literature survey, mention it here)

An analysis is made of the rate of the potential intrusion of hazardous environments in a museum facility as compared to the capacity of the exit system to evacuate the occupants.

12. KEY WORDS (Six to twelve entries; alphabetical order; capitalize only prober names; and separate key words by semicolons) egress; evacuation; fire models; fire safety; historic buildings; muserms; smoke; smoke detectors; sprinkler systems

\section{AVAILABILITY}

X] Unlimited

For Official Distribution. Do Not Release to NTIS

Order From Superintendent of Documents, U.S. Government Printing Office, Washington, D.C. 20402.

[\$ Order From National Technical Information Service (NTIS), Springfield, VA. 2216i

14. NO. OF

PRINTED PAGES

40

15. Price

$\$ 8.50$ 

